\title{
Effects of Microalgal Food Quantity on Several Productivity-Related Parameters of the Calanoid Copepod Bestiolina similis (Calanoida: Paracalanidae)
}

OPEN ACCESS

Edited by:

Sami Souissi,

Lille University of Science and Technology, France

Reviewed by:

Ricardo Calado,

University of Aveiro, Portugal

Hans Uwe Dahms,

Kaohsiung Medical University, Taiwan

*Correspondence:

Thomas Camus

thomas.camus@ifremer.fr

Jufeng Jiang

jufengjiang@163.com

${ }^{+}$Present address:

Thomas Camus,

EIO UMR24, UPF/IRD/ILM/Ifremer, Labex CORAIL, Unité RMPF, Centre

Océanologique du Pacifique, Vairao,

French Polynesia

Specialty section:

This article was submitted to Marine Fisheries, Aquaculture

and Living Resources,

a section of the journal

Frontiers in Marine Science

Received: 09 November 2021 Accepted: 30 November 2021

Published: 24 December 2021

Citation:

Camus $T$, Rolla $L$, Jiang $J$ and Zeng C (2021) Effects of Microalgal

Food Quantity on Several

Productivity-Related Parameters of the Calanoid Copepod Bestiolina

similis (Calanoida: Paracalanidae).

Front. Mar. Sci. 8:812240.

doi: 10.3389/fmars.2021.812240

\author{
Thomas Camus $^{1 * t}$, Lucrezia Rolla ${ }^{1}$, Jufeng Jiang ${ }^{2 *}$ and Chaoshu Zeng ${ }^{1}$ \\ ${ }^{1}$ Marine Ornamental Captive Breeding Research Group, College of Science and Engineering, James Cook University, \\ Townsville, QLD, Australia, ${ }^{2}$ Tianjin Ornamental Fish Technology and Engineering Centre, Tianjin Fisheries Research Institute, \\ Tianjin, China
}

The optimization of copepod feeding protocol is paramount to improve culture productivity and to maintain favorable water quality parameters overtime, as well as saving operational costs by preventing the production of unnecessary quantities of microalgae. The influence of microalgal feeding concentration on major parameters related to culture productivity of the calanoid copepod Bestiolina similis (Paracalanidae) was investigated in a series of laboratory experiments. $B$. similis was fed eight different concentrations $\left(0,150,300,600,900,1,200,1,500\right.$ and $\left.1,800 \mu \mathrm{gC} \mathrm{I}^{-1}\right)$ of a mixed microalgal diet consisting of Tahitian strain of Isochrysis species, Pavalova 50 and Tetraselmis chuii at 1:1:1 carbon ratio. The results indicate that female daily and cumulative egg production over lifespan, egg hatching rate, naupliar and copepodite survival and development, adult female life expectancy, population growth and fecal pellet production rate (FPPR) were all significantly affected by microalgae feeding ration. Conversely, no significant influence could be established between microalgae food concentration and egg diameter or adult sex ratio. Feeding rations as low as $150 \mu \mathrm{gC} \mathrm{I}^{-1}$ led to lower egg hatching rates, survival and development, adult female life expectancy and population growth compared with the higher microalgae rations tested. Feeding concentration $\leq 900 \mu \mathrm{gC} \mathrm{I}{ }^{-1}$ significantly limited female daily egg and fecal pellet production rate, as well as their cumulative egg production over lifespan, when compared to a level of $900 \mu \mathrm{gC} \mathrm{I}^{-1}$. Bestiolina similis fed with 1,200 $\mu \mathrm{gC}$ $\mathrm{I}^{-1}$ significantly improved female egg and fecal pellet production when compared to the lower treatments and was responsible for the highest female lifespan egg production and population growth observed among all treatments. Feeding rations as high as $1,500 \mu \mathrm{gC} \mathrm{I}^{-1}$ and $1,800 \mu \mathrm{gC} \mathrm{I}^{-1}$ did not lead to significant improvement in any of the parameters measured. This is likely due to a saturation effect at high food concentration which is known to decrease calanoid copepods feeding efficiency. Finally, B. similis FPPR, used as a proxy for ingestion, was found to saturate at a microalgae concentration of $783.4 \mu \mathrm{gC} \mathrm{I}^{-1}$ using a non-linear Michael-Menton (2 parameters), indicating that $\mathrm{CVI}$ female ingestion did not increase significantly above this concentration. Based on the above results it is recommended that $B$. similis 
cultures should be fed at a concentration of $1,200 \mu \mathrm{gC} \mathrm{I}^{-1}$, and not above, as rations $>1,200 \mu \mathrm{gC} \mathrm{I}^{-1}$ will not significantly improve any of the productivityrelated parameters observed in this study. Feeding rations should never be below $783.40 \mu \mathrm{gC} \mathrm{I}^{-1}$ as this is the threshold level below which adult female ingestion rates become limiting.

Keywords: copepod, food concentration, copepod culture, calanoid copepod, Paracalanidae, egg production, population growth, adult lifespan

\section{INTRODUCTION}

Marine copepods are the most abundant metazoans throughout the world's ocean (Boxshall and Halsey, 2004) and constitute the majority of plankton biomass in the epipelagic zone (Bunker and Hirst, 2004). In the wild, copepods mediate energy flow between primary producers and secondary consumers (Frost, 1972; Xu and Wang, 2001) and their naupliar stages often make up fifty percent or more of the stomach contents of early fish larvae (Sampey et al., 2007). Several commercially important planktivorous fish also rely on adult copepods for their nutrition, commonly making up as much as $39 \%$ of their stomach content (e.g., Pampus argenteus, Dadzie et al., 2000). The ubiquitous occurrence of copepods in the marine environments and their importance as natural prey items for fish larvae has prompted an increasing interest in culturing them as live feeds for marine hatcheries (Shansudin et al., 1997; O'Bryen and Lee, 2005).

Calanoid copepods are known to provide a range of crucial benefits to a variety of commercial and ornamental fish species when compared to traditional live feeds such as Artemia and rotifers (Payne and Rippingale, 2001; Drillet et al., 2006; Conceição et al., 2010). Because of their excellent track record in significantly improving the health and fitness of cultured species, calanoids are considered as the solution for larvae that cannot be reared on traditional live feeds (Marcus and Murray, 2001; O'Bryen and Lee, 2005). For example, various marine ornamental and commercial fish species, including green mandarin fish Synchiropus splendidus (Zeng et al., 2018), longsnout seahorse Hippocampus reidi (Shubert et al., 2016), cloudy damsel Dacyllus carneus (Anzeer et al., 2019) and Atlantic bluefin tuna Thunnus thynnus (Yúfera et al., 2014), have been successfully reared with significantly improved survival and growth using copepods as the first-feed. Yet, despite gaining more interest in recent years due to their obvious advantages as larval live prey over traditional live feeds, knowledge on copepod performance in intensive cultures remains limited (Abate et al., 2014; Rasdi and Qin, 2016; Jepsen et al., 2021). This under-utilization is mainly attributed to their relatively low productivity in intensive culture (Støttrup, 2000), which in turn could be partially attributed to a lack of research in the field. For instance, most of the research efforts are focused on a handful of primarily coastal calanoid species and even after several decades of study, it was estimated that fewer than $4 \%$ of marine planktonic calanoid species have had their fecundity measured (Bunker and Hirst, 2004; Marcus et al., 2004).

Although salinity and temperature are important culture parameters (Alajmi et al., 2014), existing literature suggests that copepod productivity is mainly dependent upon food quality and quantity, within the metabolic constraints set by temperature (Uye, 1981; Kleppel, 1992; Dam et al., 1994; Koski and Kuosa, 1999; Guisande et al., 2000; Tirelli and Mayzaud, 2005; Ismar et al., 2008; Pan et al., 2014; Nogueira et al., 2019).

While an optimal microalgal diet consisting of the tri-algal diet T-Iso+Tet+Pav was determined to be the optimal diet for B. similis (Camus et al., 2009; Camus and Zeng, 2010), it is also of paramount importance to evaluate the influence of microalgal quantity on its culture productivity. Hence, this study was set out to investigate the effects of various concentration of this optimal microalgal diet on major productivity-related parameters of $B$. similis with the objective to provide guidelines for optimal feeding ration for $B$. similis under intensive culture conditions.

Bestiolina similis is a small (early nauplii $<100 \mu \mathrm{m}$; adults $<700 \mu \mathrm{m}$ ) pelagic calanoid copepod belonging to the family Paracalanidae. It is considered a preferred prey item for larvae of several families of tropical fish because of its small size and excellent nutritional profile (McKinnon et al., 2003; Sampey et al., 2007). Paracalanoid copepods are widely distributed in tropical and temperate waters and frequently dominate copepod communities in surface waters (McKinnon and Duggan, 2001; Boxshall and Halsey, 2004). Over the past decade, several studies have been conducted to investigate various aspects of its culture methods (e.g., VanderLugt and Lenz, 2008; Camus et al., 2009; VanderLugt et al., 2009; Camus and Zeng, 2010).

\section{MATERIALS AND METHODS}

\section{Microalgae Culture}

A microalgal diet composed of three species of the Tahitian strain of Isochrysis species ("T-iso," class Prymnesiophyceae; CS-177), Pavalova 50 ("Pav," class Prymnesiophyceae; CS-50) and Tetraselmis chuii ("Tet," class Prasinophyceae; CS-176) was previously found to be the optimal diet for intensive culture of B. similis (Camus et al., 2009; Camus and Zeng, 2010). These microalgae species are used in marine hatcheries throughout the world and are relatively easy to maintain. For the present study, the starter cultures of the three microalgae were obtained from the Commonwealth Scientific and Industrial Research Organization (CSIRO) Microalgae Supply Service, Hobart, Tasmania, Australia. The starter cultures were gradually scaled up and finally cultured in several 20-1 polycarbonate carboys filled with $1 \mu \mathrm{m}$ filtered, autoclaved and UV irradiated seawater (salinity $30 \pm 1$ ) inside a temperature-controlled room $\left(25 \pm 1^{\circ} \mathrm{C}\right)$. The light was provided by six rows of four fluorescent tubes and photoperiod was set at $12 \mathrm{~h}$ light: $12 \mathrm{~h}$ dark with a light 
intensity of approximately 5,000 lx as measured by a MC-88 light meter (TPS Pty Ltd., Australia). The microalgae were cultured using f/2 medium (Guillard and Ryther, 1962) with vigorous aeration ( $0.2 \mu \mathrm{m}$ filtered air).

\section{Bestiolina similis Stock Culture}

Bestiolina similis were collected by a zooplankton tow at the mouth of the Ross River, Townsville, Queensland, Australia. The plankton samples were brought back to the Marine and Aquaculture Research Facility Unit (MARFU) at James Cook University, Australia, within an hour of collection. Upon arrival at the laboratory, $B$. similis were isolated in a temperaturecontrolled room $\left(27 \pm 1^{\circ} \mathrm{C}\right)$ and cultured in a salinity of $30 \pm 1$, $1 \mu \mathrm{m}$ filtered seawater. Stock cultures of $B$. similis were gradually scaled up and inoculated into several 201 plastic carboys with gentle aeration. Depending on water quality parameters, between 30 and $50 \%$ of culture water was exchanged every other day using a siphon with a $25 \mu \mathrm{m}$ mesh attached to the end to prevent the removal of any copepods. The stock cultures were entirely drained through a $150 \mu \mathrm{m}$ sieve every 10 to 15 days to remove any build-up of detritus. The $150 \mu \mathrm{m}$ sieve retained adult and copepodites, but eggs and nauplii were mostly lost. The carboys were then cleaned and sterilized with chlorine before the cultures were restarted (Camus et al., 2009; Camus and Zeng, 2010). Bestiolina similis cultures were fed daily with a trialgal diet consisting of $\mathrm{T}$-iso+Pav+Tet offered at an equal ratio of biomass based on carbon concentrations (i.e., 1:1:1 carbon ratio), which were calculated for each species according to Strathmann (1967). The trialgal diet was fed to $B$. similis at $\sim 1,500 \mu \mathrm{gC}$ $1^{-1}$, a carbon concentration known to saturate calanoid copepod feeding (Kiørboe et al., 1985).

\section{General Procedure}

All experiments were conducted at MARFU, James Cook University, Queensland, Australia. Throughout all experiments, water temperature was maintained at $27 \pm 1{ }^{\circ} \mathrm{C}$ and salinity at $30 \pm 1$ while the light regime was set at $12 \mathrm{~L}: 12 \mathrm{D}$. Observations and counting of eggs, nauplii, copepodites and adults were made using a Sedgewick-Rafter counter and a Leica CME optical microscope (model TN-PSE30, Wetzlar, Germany).

The experimental microalgae concentrations were as follow: $1,800,1,500,1,200,900,600,300,150$, and $0 \mu \mathrm{gC} 1^{-1}$. They were chosen to reflect a wide variety of food conditions, ranging from limiting to saturating, as concentrations of $300 \mu \mathrm{gC}^{-1}$ and lower are generally characterized as limiting for calanoid copepods (Koski and Klein Breteler, 2003), while 1,500 $\mathrm{gC}^{-1}$ and above are known to satiate $A$. tonsa, a similar sized planktonic copepod (Kiørboe et al., 1985). To achieve experimental microalgal concentrations, cell concentrations (cells $/ \mathrm{ml}$ ) of each microalgal species were first determined using a FlowCAM ${ }^{\mathrm{TM}}$ particle analyser, before being converted to absolute carbon concentration $\left(\mu \mathrm{gC} 1^{-1}\right.$ ) based on McKinnon et al. (2003). Microalgal cultures were subsequently combined in a 1:1:1 carbon ratio and diluted using filtered sea water to make for each of the experimental food concentrations.

A pre-conditioning period of at least one generation was ensured for each experiment. Pelagic copepods are known to acclimate to their food condition on a time scale of hours to days (Mayzaud and Poulet, 1978), and a pre-conditioning period of at least one generation was hence more than sufficient to eliminate any potential residual effect from previous feeding history.

Three experiments were conducted to test for the influences of microalgae concentration on major parameters related to $B$. similis productivity in culture, i.e., (1) daily egg production rate (EPR; egg female ${ }^{-1}$ day $^{-1}$ ), egg diameter ( $\left.\mu \mathrm{m}\right)$, egg hatching rate $(\%)$, and fecal pellet production rate (FPPR; fecal pellet.female ${ }^{-1}$.day ${ }^{-1}$ ); (2) naupliar and copepodite survival (\%), median development time from eggs to nauplii, copepodites and adult females (days), adult female life expectancy (days) and cumulative egg production over total female lifespan (eggs female $\left.{ }^{-1}\right)$; (3) population growth and sex ratio.

\section{Daily Egg and Fecal Pellet Production Experiment}

Following a pre-conditioning period to a specific feeding concentration, adult females with ripe ovaries were randomly selected and individually incubated in $60 \mathrm{ml}$ containers filled with $50 \mathrm{ml}$ of fresh sea water and microalgal food added at the designated concentrations except for the controls, in which females were starved for $48 \mathrm{~h}$ and incubated in filtered sea water without microalgal food (i.e., food ration $=0 \mu \mathrm{gC}$ $\left.1^{-1}\right)$. Each container was labeled according to its experimental food concentrations, sealed and mounted on a plankton wheel (rotation rate $=60$ cycles $/ \mathrm{h}$ ). Six replicates were set up daily for each treatment. Female egg production rate (EPR) and fecal pellet production rate (FPPR) were assessed after $24 \mathrm{~h}$. In the cases of finding a dead female after $24 \mathrm{~h}$, the replicate was discarded and its egg and fecal pellet production data were not taken into account. New replicates containers were set up daily, with fresh sea water and a new female pre-conditioned to the particular experimental food concentration. The experiment was run for 9 consecutive days. Due to variation in female survival under different food concentrations, an uneven number of replicates was obtained daily for egg production and fecal pellet production data for each treatment. However, with the replacement of invalid replicates, data from a total of 33 valid replicates $(n=33)$ were eventually achieved for each treatment.

In addition to determine daily egg and fecal pellet production, the diameters of all eggs produced on the final day of the experiment (6 replicates/treatment) were measured with a Leica CME optical microscope (model TN-PSE30). After measurement, the eggs were then incubated for hatching rates calculations. Egg hatching rate (\%) was estimated by calculating the difference between the initial number of eggs and the number of unhatched eggs observed after 48 and 96 h of incubation.

$E H S(\%)=\frac{[\text { (No. of eggs introduced initially }- \text { No. of unhatched eggs }) * 100]}{\text { No. of eggs introduced initially }}$

\section{Nauplii and Copepodites Survival and Development, Adult Female Life Expectancy and Cumulative Lifespan Egg Production Experiment}

Groups of 15 sexually mature females were randomly selected and incubated inside containers filled with $500 \mathrm{ml}$ of fresh sea 
water and fed one of the 8 designated microalgal concentration. Two males were also added to each container to ensure that female fecundity would not be affected by the absence of male. All containers were labeled with diet concentration treatment before being sealed and mounted on a plankton wheel (rotation rate $=60$ cycles $/ \mathrm{h}$ ). After $24 \mathrm{~h}$, all adult copepods were removed so that only eggs and newly hatched nauplii $(<24 \mathrm{~h})$ remained in each of the containers. All newly hatched nauplii were then recorded before gently transferring them using a broad mouth pipette to a new $500 \mathrm{ml}$ container filled with fresh sea water and with the same experimental food concentration. These new containers were labeled to allow identification of the microalgae concentration treatment and the date of the nauplii hatching. Nauplii were then reared in these containers with microalgal food concentration checked daily and adjusted to the designated experimental food concentration accordingly. Following the same procedure, new containers were set up daily for nauplii hatching during the next few days from egg produced by the females. Daily, newly hatched nauplii were set up in separated containers until all eggs had hatched and no more nauplii were found. This allowed for exact hatching date of each nauplius to be precisely recorded, allowing precise data collection about development duration. A total of 4 replicates, each containing at least 20 nauplii were conducted for each of the eight experimental food concentrations tested.

Nauplii development was closely monitored and as they started to develop into copepodites, new containers were similarly set up daily for the newly appearing copepodites. As a result, every copepodites appearing on the same day were cultured in the same container to allow precise recording of their median development duration. The same procedure was applied for the newly appeared adult females in order to allow for the estimation of median development time from egg to CVI adult.

Average naupliar survival was calculated by dividing the total number of nauplii that molted successfully into copepodites by the initial number of nauplii for each replicate and averaged for each algal concentration treatment. Average copepodite survival was similarly calculated by dividing the total number of copepodites that molted successfully to become adults by the initial number of copepodites for each treatment.

Bestiolina similis median development time (MDT) from eggs nauplii/copepodites/adult females is defined as the time when $50 \%$ of the eggs had hatched as nauplii or when $50 \%$ of population had molted to become copepodites or adult females. Median development duration was calculated using the following formula, (Peterson and Painting, 1990): $\operatorname{MDT}($ nauplii/copepodites/adult females $)=\frac{\sum_{n}^{n+1} N(\text { development stage })_{n}{ }^{*} n}{\sum N(\text { development stage })}$

Where $\mathrm{N}$ is the number of nauplii, copepodites or adult females found on a given day $n$.

Adult female life expectancy and their cumulative lifespan egg production were determined as follow: upon noticing the appearance of a mature females (CVI) in a treatment, they were individually transferred to $500 \mathrm{ml}$ containers with the same microalgal concentration. One adult male (CVI) preconditioned to the same microalgal food concentration was also added to ensure that female egg production was not limited by an absence of fertilization. The containers were then labeled, sealed and placed on a plankton wheel (rotation rate $=60 \mathrm{cycles}^{-1}$ ). Every $24 \mathrm{~h}$, each copepod pair was gently transferred to a new container filled with fresh sea water and the same microalgal concentration. The seawater in the original container was drained onto a mesh for counting the number of eggs produced by the females over the past $24 \mathrm{~h}$ period. Egg output was determined daily for each female until its death, at which point lifespan and cumulative lifespan egg production was calculated. During the experiment, any dead males found were replaced by a new male preconditioned to the same experimental food concentration.

\section{Population Growth and Sex Ratio Experiment}

For the population growth experiment, 7 preconditioned, sexually mature females and two males were introduced to a $500 \mathrm{ml}$ container and cultured under one of the eight microalgae concentration (four replicates/treatment). All experimental containers were then labeled, sealed and mounted on a plankton wheel (rotation rate $=60 \mathrm{cycles}^{-1}$ ) for a duration of 14 days, which allowed time for a second generation to be produced (Camus et al., 2009). The microalgal concentration in each container was maintained daily by adding an appropriate quantity of the trialgal diet to the container, while the build-up of detritus was gently removed using a siphon with a $25 \mu \mathrm{m}$ mesh sieve attached to its end to prevent the removal of any life stage of $B$. similis. After 14 days, all replicates were drained through a $25 \mu \mathrm{m}$ sieve and all retained eggs, nauplii, copepodites and adults were fixed using a $10 \%$ buffered formalin fixative for later counting and sexing of all adults. The intrinsic rate of population increase $r$ was then calculated for each treatment using the formulation:

$$
r=\frac{\ln \left(\frac{\mathrm{N}_{0}}{\mathrm{~N}_{1}}\right)}{\mathrm{t}}
$$

Where $\mathrm{N}_{0}=$ population number at the beginning of the experiment, $\mathrm{N}_{1}$ = population number at the end of the experiment while $t$ (days) is the duration of the experiment (Fenchel, 1974).

\section{Data Collection and Analysis}

Data are presented as mean \pm standard error (SE). Egg production rate, fecal pellet production rate, egg hatching rate, female proportion, female live expectancy, female total egg production, population growth and median development data were confirmed to meet the parametric test assumptions (i.e., balanced study design, normally distributed, homogeneity of variance) and were analyzed using one-way ANOVA. When a significant difference $(p<0.05)$ was detected, the Tukey's multiple comparisons test was used to determine specific differences among treatments $(p<0.05)$. Egg diameter size data did not meet the parametric test assumptions and a KruskalWallis test was used for statistical analysis. If a significant difference $(p<0.05)$ was detected, a multiple comparison of mean ranks was used to determine specific differences 
among treatments $(p<0.05)$. Data on egg hatching rate data were log transformed and pooled across all replicates for each treatment before being analyzed for significant difference between treatments, using the Chi square test. All statistical analyses were conducted using Statistica ${ }^{\mathrm{TM}}$ version 8 .

The correlation between fecal pellet production rates and microalgal diet concentrations was assessed using nonlinear regression analysis in SigmaPlot ${ }^{\mathrm{TM}}$ (version 11). The non-linear Michael-Menton equation (2 parameters; Holling, 1959) was used to describe the relationship between female fecal pellet production rate (fecal pellets female ${ }^{-1} \mathrm{day}^{-1}$ ) and microalgae concentration $\left(\mu \mathrm{gC}^{-1}\right)$ :

$$
y=\frac{\mathrm{a} * \mathrm{x}}{\mathrm{c}+\mathrm{x}}
$$

where $\mathrm{y}$ is the fecal pellet production rate and $\mathrm{x}$ is the microalgae concentration, $\mathrm{a}$ is the maximum rate of fecal pellet production and $\mathrm{c}$ is the half saturation rate (microalgae concentration that produce $50 \%$ of the highest $y$ value).

\section{RESULTS}

\section{Daily Egg and Faecal Pellet Production, Egg Size and Hatching Success}

Microalgal concentration had a significant effect $(p<0.05)$ on egg production rate (EPR), fecal pellet production rate (FPPR) as well as 48 and $96 \mathrm{~h}$ egg hatching rate (EHR) (Table 1). However, average egg diameter was not significantly affected $(p>0.05)$. B. similis fed at $1,500 \mu \mathrm{gC}^{-1}$ exhibited the highest EPR $\left(22.6 \pm 1.4\right.$ eggs female ${ }^{-1}$ day $\left.^{-1}\right)$, significantly higher than all other treatments except for the 1,800 and $1,200 \mu \mathrm{gC} \mathrm{l}^{-1}$ treatments $\left(18.6 \pm 1.4\right.$ and $20.1 \pm 1.2$ eggs female ${ }^{-1}$ day $^{-1}$, respectively). Results also showed that $B$. similis fecundity was significantly limited when the daily food ration was below $1,200 \mu \mathrm{gC}^{-1}$ (Table 1). When the unfed control is excluded from the data analysis, the lowest EPR $\left(2.2 \pm 0.2\right.$ eggs female ${ }^{-1}$ day $^{-1}$ ) was found at the lowest food concentration $\left(150 \mu \mathrm{gCl}^{-1}\right)$, significantly lower than all other treatments except for $300 \mu \mathrm{gC}$ $1^{-1}\left(4.4 \pm 0.5\right.$ eggs female ${ }^{-1}$ day $\left.^{-1}\right)$.

Bestiolina similis fecal pellet production rate was also significantly influenced by microalgae concentration (Table 1). The highest FPPR was found at $1,500 \mu \mathrm{gC}^{-1}(206.4 \pm 11.5 \mathrm{fecal}$ pellets female ${ }^{-1}$ day $^{-1}$ ), not significantly different from those of the 1,800 and $1,200 \mu \mathrm{gC} \mathrm{l}^{-1}$ treatments $(182.8 \pm 10.1$ and $197.9 \pm 10.1$ fecal pellets female ${ }^{-1}$ day $^{-1}$ ) (Table 1). Conversely, relatively low FPPR were found when $B$. similis was reared using a $150 \mu \mathrm{gC}^{-1}$ food ration $\left(80 \pm 6\right.$ fecal pellets female ${ }^{-1}$ day $\left.^{-1}\right)$, significantly different from all other treatments except the $300 \mu \mathrm{gC}^{-1}$ treatment $\left(106 \pm 6\right.$ fecal pellets female ${ }^{-1}$ day $^{-1}$, indicating a limiting of ingestion for $B$. similis females when reared using such low food concentrations. Lastly, the FPPR observed in the control was negligible (Table 1).

In order to determine with precision, the threshold above which $B$. similis ingestion rate starts to saturate, CVI female FPPR was plotted as a function of microalgae concentration (Figure 1 and see Table 2 for details). Bestiolina similis FPPR was found to saturate at a microalgal concentration of $783.40 \mu \mathrm{gC}$ $1^{-1}$ (Figure 1).

Bestiolina similis 48- and 96-h egg hatching rate (EHR) were both significantly influenced $(p<0.05)$ by microalgal concentration. Eggs produced at the $150 \mu \mathrm{gC}^{-1}$ treatment had the lowest 96-h EHR, significantly different from the higher concentrations tested (Table 1). Microalgae rations of $300 \mu \mathrm{gC}$ $1^{-1}$ and above did not produced significantly different EHS from one another, with $48 \mathrm{~h} \mathrm{EHR}>83 \%$ and $96 \mathrm{~h} \mathrm{EHR}>89 \%$ for food concentrations contained between 300 and $1,800 \mu \mathrm{gC} \mathrm{l}^{-1}$.

\section{Naupliar and Copepodite Survival and Development, Adult Female Life Expectancy and Lifespan Cumulated Egg Production}

Naupliar survival was relatively high $(\geq 85 \%)$ for microalgae concentrations higher than $300 \mu \mathrm{gC}^{-1}$ and no significant difference was detected among treatments $(p>0.05$; Table 3). However, a significantly lower survival of $65 \%$ $(p<0.05)$ was recorded when a food concentration as low as $150 \mu \mathrm{gC}^{-1}$ was fed to $B$. similis. As for nauplii, copepodites survival was also reasonably high $(\geq 80 \%)$ when reared at concentrations $\geq 600 \mu \mathrm{gC} 1^{-1}$, with no significant difference detected between treatments. However, a significant decrease of survival to $52 \pm 5 \%$ was observed when food ration was decreased to $300, \mu \mathrm{gC}^{-1}$. Further reduction of microalgae concentration to $150 \mu \mathrm{gC}^{-1}$ led to further decreased in copepodite to only $39 \pm 3 \%$. It is interesting to note that copepodite survival was consistently lower than their naupliar counterparts under similar microalgal ration (Table 3 ).

The median development time (MDT) from egg to nauplius, to copepodite and to adult female were all significantly affected $(p<0.05)$ by microalgal concentration (Table 3$)$. Copepodites started to appear on day 3 and the MDT from eggs to copepodites was $\leq 3.86$ days with no significant difference among treatments when microalgae rations was $\geq 300 \mu \mathrm{gC} 1^{-1}$. However, when microalgae concentration decreased to $150 \mu \mathrm{gC}^{-1}$, the MDT increased significantly to $4.52 \pm 0.12$ day (Table 3 ). CVI sexually mature adults started to appear on day 5 of the trial and MDT from eggs to adults was shorter than 6 days when food concentration was $\geq 600 \mu \mathrm{gC}^{-1}$. The MDT from eggs to CVI adults was significantly increased to $7.46 \pm 0.10$ days at the lowest food ration of $150 \mu \mathrm{gC}^{-1}$ (Table 3).

Eggs produced at the two lowest microalgae concentrations tested (150 and $\left.300 \mu \mathrm{gC}^{-1}\right)$ had the longest egg incubations times ( $2.94 \pm 0.02$ and $2.35 \pm 0.01$ days, respectively) significantly longer $(p<0.05)$ than the rest of the treatments, while the $150 \mu \mathrm{gC} \mathrm{l}^{-1}$ treatment was significant longer than the $300 \mu \mathrm{gC} 1^{-1}$ treatment (Table 3). There was no significant different difference in egg incubation time among the other treatments (Table 3).

Figure 2 represents the average life expectancy of $B$. similis CVI females from different microalgal feeding concentrations. The CVI females had the longest life expectancy after reaching sexual maturity (6.9-7.1 days) when they were fed at a concentration between $300-900 \mu \mathrm{gC} \mathrm{l}^{-1}$, while those from 


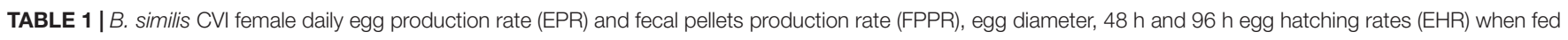
different concentrations of a trialgal diet (T-Iso+Tet+Pav) at a 1:1:1 carbon ratio.

\begin{tabular}{|c|c|c|c|c|c|}
\hline $\begin{array}{l}\text { Food concentration } \\
\left(\mu \mathrm{gC} \mathrm{I}^{-1}\right)\end{array}$ & $\begin{array}{c}\text { EPR (eggs female }{ }^{-1} \\
\text { day }^{-1} \text { ) }\end{array}$ & $\begin{array}{l}\text { FPPR (fecal pellets } \\
\text { female }^{-1} \text { day }^{-1} \text { ) }\end{array}$ & Egg diameter $(\mu \mathrm{m})$ & 48 h EHR (\%) & 96 h EHR (\%) \\
\hline 1800 & $18.6 \pm 1.4^{a}$ & $182.8 \pm 10.2^{A}$ & $81.64 \pm 0.93$ & $83.0 \pm 2.0^{f g}$ & $90.7 \pm 1.7^{\mathrm{F}}$ \\
\hline 1500 & $22.6 \pm 1.4^{a}$ & $206.4 \pm 11.5^{\mathrm{A}}$ & $83.48 \pm 1.05$ & $85.2 \pm 2.1^{f}$ & $93.7 \pm 1.0^{\mathrm{F}}$ \\
\hline 1200 & $20.1 \pm 1.2^{a}$ & $197.9 \pm 10.1^{\mathrm{A}}$ & $83.89 \pm 0.85$ & $85.5 \pm 2.4 \mathrm{fg}$ & $89.3 \pm 1.2^{\mathrm{F}}$ \\
\hline 900 & $12.7 \pm 0.8^{b}$ & $140.0 \pm 6.7^{B}$ & $84.16 \pm 0.74$ & $86.8 \pm 1.9^{f}$ & $92.8 \pm 1.0^{\mathrm{F}}$ \\
\hline 600 & $6.9 \pm 0.6^{c}$ & $125.5 \pm 6.0^{B}$ & $87.04 \pm 1.23$ & $84.3 \pm 1.7^{\mathrm{fg}}$ & $90.7 \pm 1.2^{\mathrm{F}}$ \\
\hline 300 & $4.4 \pm 0.5^{c d}$ & $106.1 \pm 5.9^{B C}$ & $85.94 \pm 1.35$ & $83.3 \pm 2.1^{\mathrm{fg}}$ & $90.7 \pm 0.7^{\mathrm{F}}$ \\
\hline 150 & $2.2 \pm 0.2^{d}$ & $80.3 \pm 5.9^{C}$ & $84.08 \pm 1.08$ & $76.0 \pm 1.8^{\mathrm{g}}$ & $83.3 \pm 1.0^{\mathrm{G}}$ \\
\hline 0 & $(0.3 \pm 0.2)$ & $(13.8 \pm 1.3)$ & $\mathrm{n} / \mathrm{a}$ & $\mathrm{n} / \mathrm{a}$ & $\mathrm{n} / \mathrm{a}$ \\
\hline
\end{tabular}

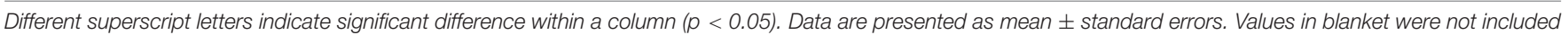
for statistical analysis due to few replicates retrieved. $n / a$ indicates that not enough data were obtained to calculate reliable average.

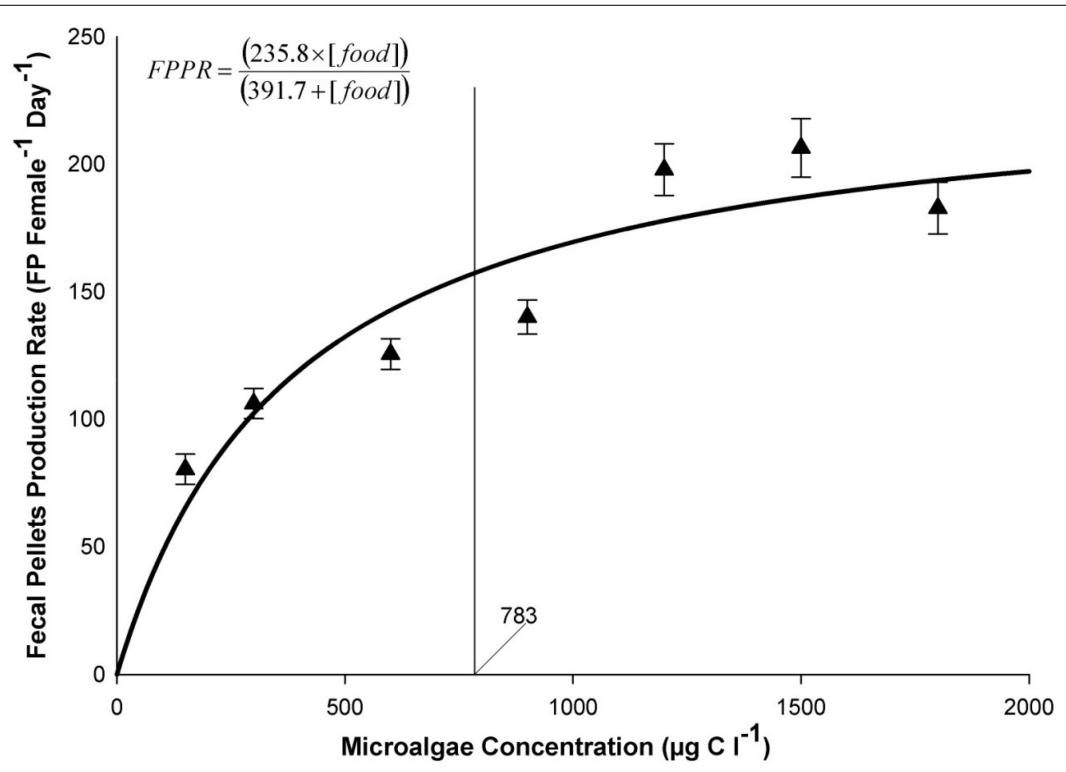

FIGURE 1 | Relationship between fecal pellet production rates and concentration of a mixed trialgal diet (T-Iso+Tet+Pav at a 1:1:1 carbon ratio) in the calanoid copepod B. similis. Each data point represents average \pm standard error. The vertical line is the carbon concentration to which fecal pellet production saturates. Curves were fitted using SigmaPlot ${ }^{\mathrm{TM}}$ (v11.0) using an iterative process.

TABLE 2 | Summary of the model parameters and results for B. similis CVI female.

\begin{tabular}{|c|c|c|c|c|c|c|c|c|c|}
\hline Dependent variable & Function & Equation & $\mathbf{a}$ & b & c & Saturation point $\left(\mu \mathrm{gC} \mathrm{I}^{-1}\right)$ & $R^{2}$ & $R^{2}$ adj & $\mathbf{p}$ \\
\hline Female FPPR & $\begin{array}{l}\text { Michaelis-Menton, } \\
\text { two parameters }\end{array}$ & $y=\left(a^{*} x\right) /(b+x)$ & 235.82 & 391.70 & $\mathrm{n} / \mathrm{a}$ & 783.40 & 0.86 & 0.83 & $<0.03$ \\
\hline
\end{tabular}

The nonlinear Michaelis-Menton equation was used to describe the relationship between microalgae concentration ( $\mu$ gC ${ }^{-1}$ ) and fecal pellet production rate (fecal pellets female $\left.e^{-1} d a y^{-1}\right)$. " $R^{2}$ " is the coefficient of determination, " $R^{2}$ adj" is the adjusted coefficient of determination and " $p$ " is the significance level of the fit.

higher concentration treatments (between 1,200 and $-1,800 \mu \mathrm{gC}$ $1^{-1}$ ) had a shorter life expectancy (6.0-6.5 days), although the differences between all above treatments were not statistically significant $(p>0.05)$. The shortest average female lifespan $(4.7 \pm 0.8$ days) was recorded at the lowest food ration treatment of $150 \mu \mathrm{gC} \mathrm{l}^{-1}$, which was significantly shorter than the 300,600 , and $900 \mu \mathrm{gC} 1^{-1}$ treatments but not significantly different $(p<0.05)$ from the $1,200,1,400$ and $1,800 \mu \mathrm{gC}^{-1}$ treatments (Figure 2).
Microalgal feeding concentration had a similarly significant influence of cumulative egg output over the lifespan of $B$. similis females ( $p>0.05$; Figure 3 ) with the higher total egg productions found at algal concentrations of $1,200,1,500$, and $1,800 \mu \mathrm{gC}^{-1}$ $\left(140.6 \pm 10.4 ; 130.6 \pm 10.0\right.$ and $132.3 \pm 8.6$ eggs female fer $^{-1}$ respectively), significantly higher than those found at lower concentrations from 150 to $900 \mu \mathrm{gC} \mathrm{l}^{-1}$ treatments $(p>0.05)$. Among these lower concentrations, the 600 and $900 \mu \mathrm{gC} \mathrm{l}^{-1}$ treatments produced intermediate lifespan global egg output 


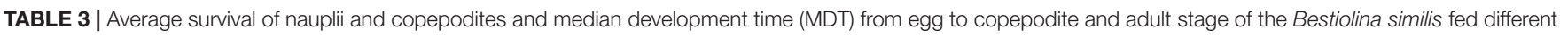
concentrations of a trialgal diet T-Iso+Tet+Pav with a 1:1:1 carbon ratio.

\begin{tabular}{|c|c|c|c|c|c|}
\hline $\begin{array}{l}\text { Microalgal concentration } \\
\left(\mu \mathrm{gC} \mathrm{I}^{-1}\right)\end{array}$ & $\begin{array}{l}\text { MDT from eggs to } \\
\text { nauplii (days) }\end{array}$ & Naupliar survival (\%) & $\begin{array}{l}\text { MDT from egg to } \\
\text { copepodite (days) }\end{array}$ & $\begin{array}{l}\text { Copepodite survival } \\
(\%)\end{array}$ & $\begin{array}{l}\text { MDT from egg to CVI } \\
\text { adult (days) }\end{array}$ \\
\hline 1800 & $2.14 \pm 0.04^{a}$ & $95 \pm 2^{d}$ & $3.80 \pm 0.08^{f}$ & $92 \pm 2^{h}$ & $5.93 \pm 0.07^{k}$ \\
\hline 1500 & $2.16 \pm 0.01^{a}$ & $94 \pm 2^{d}$ & $3.78 \pm 0.08^{f}$ & $90 \pm 2^{h}$ & $5.94 \pm 0.08^{k}$ \\
\hline 1200 & $2.16 \pm 0.04^{a}$ & $94 \pm 3^{d}$ & $3.80 \pm 0.13^{f}$ & $91 \pm 3^{h}$ & $5.96 \pm 0.10^{k}$ \\
\hline 900 & $2.17 \pm 0.03^{a}$ & $92 \pm 5^{d}$ & $3.74 \pm 0.04^{f}$ & $81 \pm 2^{h}$ & $5.91 \pm 0.05^{k}$ \\
\hline 600 & $2.14 \pm 0.01^{a}$ & $96 \pm 3^{d}$ & $3.86 \pm 0.06^{f}$ & $80 \pm 2^{h}$ & $6.00 \pm 0.05^{k}$ \\
\hline 300 & $2.35 \pm 0.01^{b}$ & $85 \pm 1^{d}$ & $3.83 \pm 0.08^{f}$ & $52 \pm 5^{i}$ & $6.18 \pm 0.08^{k}$ \\
\hline 150 & $2.94 \pm 0.02^{c}$ & $65 \pm 3^{e}$ & $4.52 \pm 0.12^{g}$ & $39 \pm 3^{j}$ & $7.46 \pm 0.10^{1}$ \\
\hline
\end{tabular}

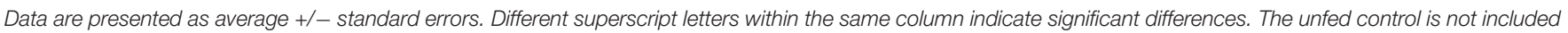
as development was not observed controls as development was not observed beyond the second nauplius stage (NII) due to starvation.

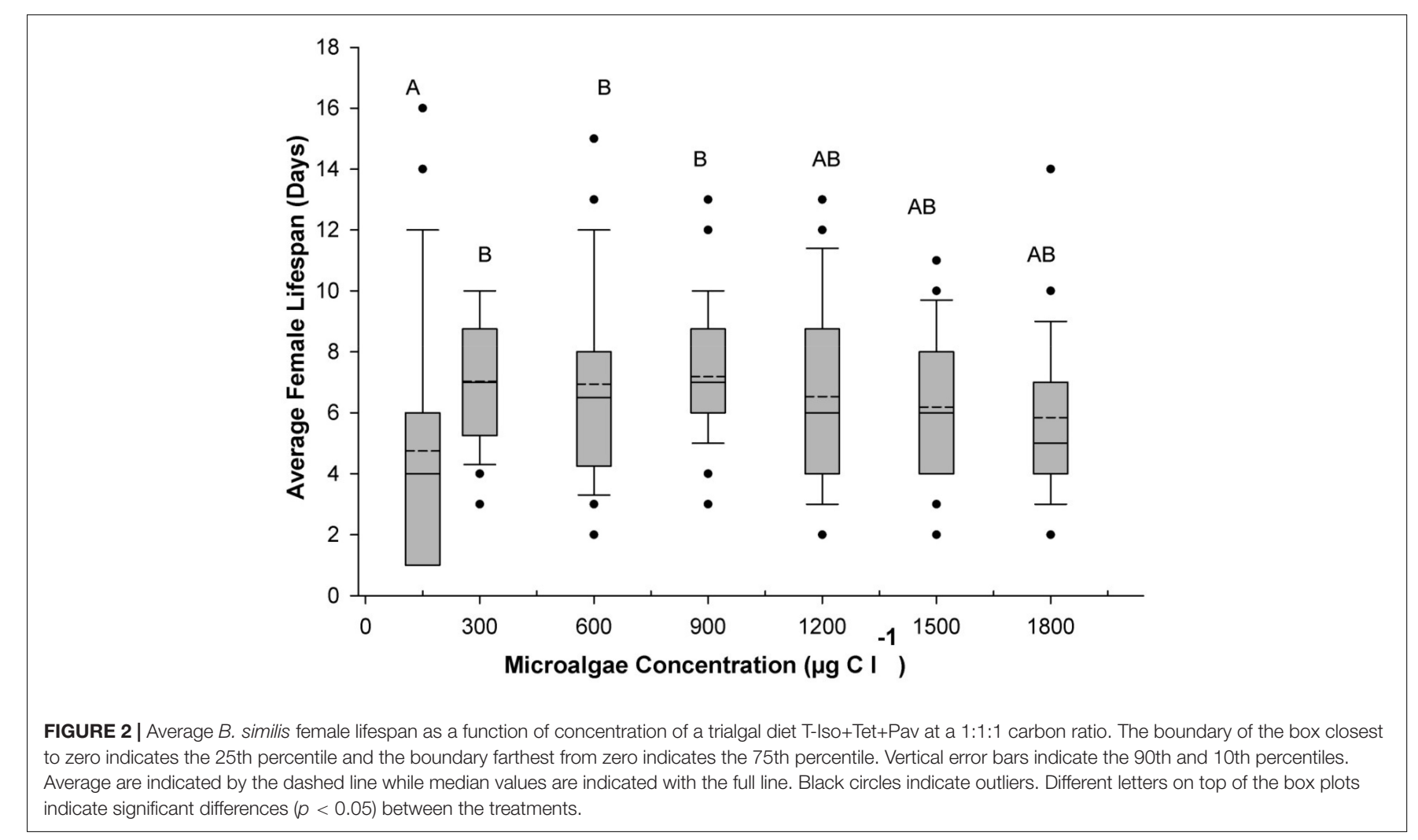

$\left(79.7 \pm 6.4\right.$ and $100.8 \pm 7.3$ eggs female $e^{-1}$, respectively), which were significantly higher than the 150 and $300{\mu \mathrm{gCl}^{-1}}^{-1}(p<0.05)$. The lowest total egg output recorded was $38.3 \pm 3.7$ eggs female $^{-1}$ in the $150 \mu \mathrm{gC} \mathrm{l}^{-1}$ treatment although it was not significantly different from that of the $300 \mu \mathrm{gC} \mathrm{l}^{-1}$ treatment $(p>0.05$; Figure 3).

\section{Population Growth and Composition}

After 14 days of culture, population increase of $B$. similis was significantly $(p<0.05)$ affected by microalgae concentration, whether or not unhatched eggs are considered in the final count (Table 4). Copepods reared using a $1,200 \mu \mathrm{gC} 1^{-1}$ food ration had the highest intrinsic rate of population increase $(0.27 \pm 0.01)$ although it was not significantly different from the other treatments except for the $150 \mu \mathrm{gC}^{-1}$ treatment, which was the only treatment to produce a negative intrinsic rate of population increase $(-0.03 \pm 0.03)$ (Table 4$)$. At the end of the experiments, sex ratio of adults in the final populations was consistently heavily skewed toward females (i.e., between 80 and $94 \%$ of adults were females) in all treatments and no significant effect of algal feeding concentrations on sex ratio was detected $(p>0.05)$ (Table 4).

\section{DISCUSSION}

Microalgal concentration is long established as one of the key factors affecting copepod productivity (Klein Breteler and Gonzalez, 1982, 1988; Klein Breteler et al., 1995; 


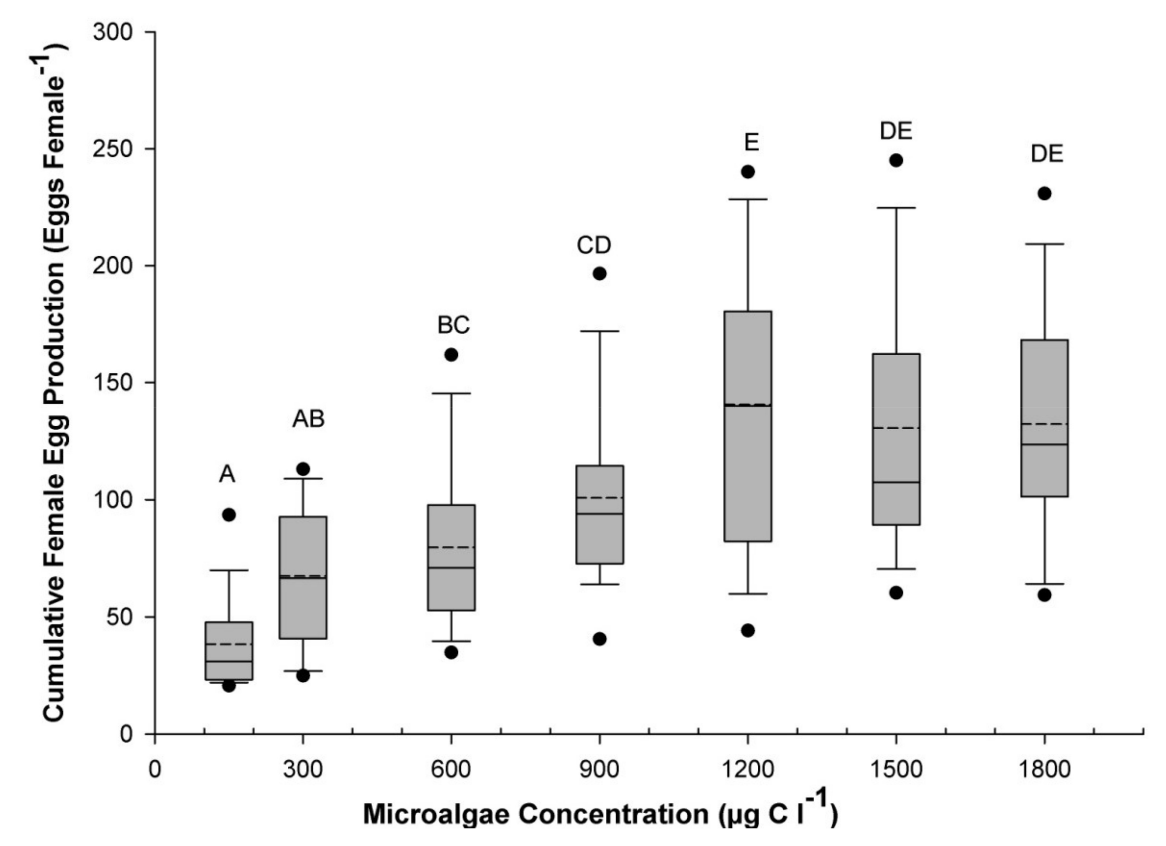

FIGURE 3 | Average total egg production over B. similis female lifespan as a function of concentration of a trialgal diet T-Iso+Tet+Pav. The boundary of the box closest to zero indicates the 25th percentile and the boundary farthest from zero indicates the 75th percentile. Vertical error bars indicate the 90 th and 10 th percentiles. Average are indicated by the dashed line while median values are indicated with the full line. Dark circles indicate outliers. Different letters on top of the box plots indicate significant differences $(p<0.05)$ between the treatments.

TABLE 4 | Final population and intrinsic rate $(r)$ of population increase of $B$. similis cultured over a 14 days period fed on different concentration of a trialgal diet T-Iso+Tet+Pav at a 1:1:1 carbon ratio.

\begin{tabular}{|c|c|c|c|c|}
\hline $\begin{array}{l}\text { Microalgal concentration } \\
\left(\mu \mathrm{gC} \mathrm{I}^{-1}\right)\end{array}$ & $\begin{array}{c}\text { Intrinsic rate of } \\
\text { population increase }\end{array}$ & $\begin{array}{c}\text { Final population } \\
\text { number when all } \\
\text { stages are included }\end{array}$ & $\begin{array}{c}\text { Final population } \\
\text { number of all } \\
\text { post-egg-stages }\end{array}$ & $\begin{array}{c}\text { Final female } \\
\text { proportion (\%) }\end{array}$ \\
\hline 1800 & $0.25 \pm 0.01 \mathrm{a}$ & $323.5 \pm 45.88$ & $243.5 \pm 35.32$ & $0.91 \pm 0.03$ \\
\hline 1500 & $0.25 \pm 0.01 \mathrm{a}$ & $297 \pm 26.89$ & $254.75 \pm 23.47$ & $0.92 \pm 0.01$ \\
\hline 1200 & $0.27 \pm 0.01 \mathrm{a}$ & $433.25 \pm 76.88$ & $345 \pm 71.51$ & $0.94 \pm 0.04$ \\
\hline 900 & $0.25 \pm 0.01 \mathrm{a}$ & $327.25 \pm 40.31$ & $241.5 \pm 38.21$ & $0.87 \pm 0.03$ \\
\hline 600 & $0.23 \pm 0.01 \mathrm{a}$ & $237.5 \pm 27.02$ & $179.5 \pm 28.00$ & $0.83 \pm 0.01$ \\
\hline 300 & $0.21 \pm 0.02 \mathrm{a}$ & $182.5 \pm 49.11$ & $162 \pm 49.48$ & $0.80 \pm 0.02$ \\
\hline 150 & $-0.03 \pm 0.03 b$ & $7.75 \pm 3.77$ & $7.25 \pm 3.28$ & $(0.95 \pm 0.04)$ \\
\hline
\end{tabular}

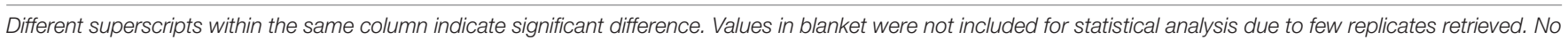
enough data were retrieved from the controls as development was not observed beyond the second nauplius stage (NII) due to starvation.

Tirelli and Mayzaud, 2005) and over the past decade many studies have reporting effects of food quality (or algal species) on copepod culture productivity (e.g., Milione and Zeng, 2007; Camus et al., 2009; Camus and Zeng, 2010; Pan et al., 2014; Alajmi and Zeng, 2015; Rasdi and Qin, 2018; Nogueira et al., 2019; Dayras et al., 2020). However, investigations on effects of food quantity (or algal concentration) are far fewer, particularly studies considering copepods as live prey in aquaculture settings. Results from an ecological study conducted in Hawaii reported that $B$. similis naupliar stages selected strongly against prey particles in the $2-5 \mu \mathrm{m}$ range and a total ingestion rate of 25.473.8 ng $\mathrm{C}$ nauplius ${ }^{-1} \mathrm{~h}^{-1}$ (Jungbluth et al., 2017). However, this study is focused exclusively on $B$. similis naupliar stages and levels of food concentrations reflecting those found in the natural environment. In an effort to improve the culture protocol of Bestiolina. similis, a promising live prey for marine hatcheries (McKinnon et al., 2003), the present study was designed to determine the effects of eight different feeding concentrations ( 0 to $1,800 \mu \mathrm{gC}^{-1}$ ) of a pre-determined optimized trialgal diet (Camus et al., 2009; Camus and Zeng, 2010) on several major productivity-related parameters on CVI adult B. similis.

The optimization of microalgal feeding rations is of paramount importance in a commercial copepod culture setting for several reasons: to ensure that the culture productivity is not limited by microalgae quantity; to limit the accumulation of excess uneaten microalgae that can potentially negatively impact water quality parameters overtime and to save significant amount of time and effort culturing unneeded additional algal biomass, 
ultimately cutting down operational costs and saving precious worker's time. Several field studies have demonstrated that the ingestion rates of pelagic copepods were seldom saturated in the wild, even during events of phytoplankton blooms (Mayzaud and Poulet, 1978; Ayukai, 1987; Liang et al., 1994; Hirst and Lampitt, 1998), making it quite difficult to accurately determine their feeding saturation rates in situ. Conversely, food conditions can be precisely monitored in laboratory settings and saturations of copepod ingestion rates have commonly been measured (Corner et al., 1972; Frost, 1972; Uye, 1981; Tirelli and Mayzaud, 2005; Gusmão and McKinnon, 2009a). Experiment conducted under laboratory setting therefore helps to understand the full spectrum of copepod responses to food quantity, including higher, limiting food concentrations (Støttrup and Jensen, 1990).

Calanoid copepods are known to contain mostly lipids, such as triacylglycerols, that only reflect recent nutritional conditions rather than prolongated feeding history (Koski and Kuosa, 1999). The negligible amount of eggs and fecal pellets production observed for $B$. similis in the unfed control $\left(0 \mu \mathrm{gC} \mathrm{l}^{-1}\right)$ confirmed this hypothesis, as no residual effect from previous feeding history was measured.

The lowest microalgal concentration tested $\left(150 \mu \mathrm{gC}^{-1}\right)$ produced the lowest egg production, egg hatching rate, naupliar and copepodite survival and development, adult female life expectancy as well as a negative population growth over a 14 days period of culture. This is consistent with reports of generation time increasing with decreasing food quantity, as reported in previously studies on calanoid copepods (Arnott et al., 1986; Ban, 1994). Higher algal feeding concentration $\geq 300 \mu \mathrm{gC} \mathrm{l}^{-1}$ significantly improved several productivity related parameters, such as egg hatching rate, naupliar and copepodite survival and development, and was capable of supporting positive population growth over 14 days. However, microalgal concentrations $\leq 900 \mu \mathrm{gC}^{-1}$ were still limiting regarding daily egg and fecal pellet production, as well as female cumulative egg production over lifespan, when compared to microalgae concentrations $>900 \mu \mathrm{gC} 1^{-1}$. These results suggest that microalgal feeding concentrations of $900 \mu \mathrm{gC}^{-1}$ and below are still somehow limiting to $B$. similis productivity.

Bestiolina similis cultured using a microalgal concentration of $1,200 \mu \mathrm{gC} \mathrm{l}^{-1}$ experienced the highest cumulative egg production over female lifespan and the highest population growth among all tested concentrations. Increasing this ration further to 1,500 or even $1,800 \mu \mathrm{gC} 1^{-1}$ did not produce any significant improvement in any of the productivityrelated parameters measured, suggesting a stagnation in feeding efficiency for feeding rations $>1,200 \mu \mathrm{gC}^{-1}$. Such a result can probably be explained by "dome-shaped" functional responses proposed by Jeschke et al. (2004), who suggested that a decrease in consumption rate by filter feeders may occur at very high food abundance due to confusion, clogging of feeding appendages and/or accumulation of toxic substances produced by excessively high food concentrations (Jeschke et al., 2004). These mechanisms could be responsible in diminishing calanoid copepods ingestion rate during episodes of excessive food abundance and are not always taken into consideration when modeling deposit/filter feeders' functional responses in natural settings. Indications of decreasing productivity at higher food concentrations were observed in the current experiment, as the $1,800 \mathrm{MgC}^{-1}$ treatment produced lower daily egg and fecal pellet production, decreased female life expectancy and cumulative egg production over lifespan, as well as population growth when compared to the $1,200 \mu \mathrm{gC}^{-1}$ treatment. To conduct additional treatments at food concentration $>1,800 \mu \mathrm{gC} 1^{-1}$ could have provided a more complete representation of $B$. similis dome-shaped response due to saturation of feeding under excessive food rations.

Although no significant difference in sex ratio was detected among the microalgae concentrations tested, $B$. similis sex ratio was always highly skewed toward females for all treatments (8094\% adults were females). While sex-determination mechanisms in calanoid copepods remain largely unknown, this highly skewed sex ratios could be explained by the intersexuality mechanism postulated by Gusmão and McKinnon (2009b) in which under certain environmental conditions, a sex change occurs during the late copepodite development. Copepod population in culture strongly skewed toward females are a significant advantage in hatchery setting, as they will produce more eggs at the population level, providing there is no limitation in fertilization due to a low abundance of males.

A 14 days population growth experiment provided positive intrinsic rates of population increase for all microalgae concentrations tested, with the exception for the $150 \mu \mathrm{gC} \mathrm{l}^{-1}$ treatment. Such a low food concentration should hence be avoided in $B$. similis culture as it was too low to support any growth in population over a 14 days period. Interestingly, food concentration ranging from 300 to $1,800 \mathrm{gC} \mathrm{l}^{-1}$ did not produce a significantly different final intrinsic rates of population increase.

Individual CVI females were used to allow data collection for female life expectancy and cumulative egg production over lifespan. Past studies have reported contradicting results on effects of crowding on copepod egg production. For example, Zhang et al. (2015) demonstrated that high stocking density (40-160 individuals $1^{-1}$ ) depressed daily egg production of the temperate species Acartia tonsa when fed algae Rhinomonas reticulate at $\geq 500 \mu \mathrm{gC} 1^{-1}$. Nevertheless, the same authors concluded that egg production was mainly limited by the quantity of food rather than crowding. In Acartia sinjiensis, it was, however, found that within a broad range of stocking density (125-2,000 individuals $1^{-1}$ ), average daily egg output per female was not significantly affected by this parameter (Camus and Zeng, 2009). The present study did not test for density effect and it is hence unknown whether or not $B$. similis egg production is affected by crowding, which warrants further research.

Food concentration is known to affect the physical characteristics of copepod fecal pellets (Besiktepe and Dam, 2002), the production rates of which are commonly used as a proxy of ingestion rate (Ayukai, 1987; Besiktepe and Dam, 2002). Ingestion rate is not simply related to food quantity but rather to the combined interactions of food quality and quantity with ingestion, gut transit time and assimilation efficiency (Mitra and Flynn, 2007). Gut residence time tend to increase during episodes of high food concentration, producing large 
and densely packed fecal pellets (Dagg and Walser, 1986). On the other hand, decrease in gut residence time during episodes of low food concentrations is believe to save the energy cost of ingestion, as copepods are unable to extract much from the ingested materials, resulting in the production of smaller, less dense and more fragile fecal pellets (Mitra and Flynn, 2007). This was confirmed in the present study as visual inspection of the fecal pellets revealed that smaller, less dense pellets of inconsistent shape were produced at food rations of 150 and $300 \mu \mathrm{gC}^{-1}$, whereas comparatively larger and denser fecal pellets of consistent shape were found at food rations of $600 \mathrm{\mu gC}^{-1}$ and above. Nonetheless, there are indications that this relationship between food concentration and gut transit time might be species-specific, as other studies reported a decrease in gut transit time associated with increasing concentration of certain food types such as diatoms (Tirelli and Mayzaud, 2005).

Results from this study suggest that marine hatcheries should pay closer attention to improving microalgal feeding for the intensive cultivation of calanoid copepods. Implementing an optimal microalgal feeding ration that will ensure maximum culture productivity, without saturating copepod feeding capacity, provides numerous advantages to a copepod culture, including improving water quality parameters overtime, while saving time and money. In the case of $B$. similis, a trialgal diet of T-Iso+Tet+Pav at 1:1:1 carbon ratio should be fed at a concentration of $1,200 \mu \mathrm{gC} \mathrm{l}^{-1}$ and not above, as rations $>1,200 \mu \mathrm{gC} \mathrm{l}^{-1}$ will not provide any significant improvement in productivity. On the other hand, feeding rations should never be allowed to drop below $783.40 \mu \mathrm{gC}^{-1}$ as this is the threshold level below which adult female ingestion rates become limiting.

\section{REFERENCES}

Abate, T. G., Nielsen, R., Nielsen, M., Drillet, G., Jepsen, P. M., and Hansen, B. W. (2014). Economic feasibility of copepod production for commercial use: result from a prototype production facility. Aquaculture 436, 72-79. doi: 10.1016/j. aquaculture.2014.10.012

Alajmi, F., and Zeng, C. (2015). Evaluation of microalgal diets for the intensive cultivation of the tropical calanoid copepod, Parvocalanus crassirostris. Aquac. Res. 46, 1025-1038. doi: 10.1111/are.12254

Alajmi, F., Zeng, C., and Jerry, D. R. (2014). Improvement in the reproductive productivity of the tropical calanoid copepod Parvocalanus crassirostris through selective breeding. Aquaculture 420-421, 18-23. doi: 10.1016/j. aquaculture.2013.10.031

Anzeer, F. M., Aneesh, K. S., Abraham, M. V., Darsana, S., Santhosh, B., Anil, M. K., et al. (2019). Breeding, early development and larval rearing of cloudy damsel, Dascyllus carneus Fischer, 1885. Aquaculture 505, 374-385. doi: 10. 1016/j.aquaculture.2019.03.001

Arnott, G., Brand, G., and Kos, L. (1986). Effects of food quality and quantity on the survival, development, and egg production of Gladioferens Pectinatus (Brady) (copepoda: calanoida). Mar. Fresh. Res. 37:467. doi: 10.1071/mf986 0467

Ayukai, T. (1987). Feeding by the planktonic calanoid copepod Acartia clausi on natural suspended particulate matter of varying quantity and quality. J. Exp. Mar. Biol. Ecol. 106, 137-149. doi: 10.1016/0022-0981(87)90152-3

Ban, S. (1994). Effect of temperature and food concentration on post-embryonic development, egg production and adult body size of calanoid copepod Eurytemora affinis. J. Plankton Res. 16, 721-735. doi: 10.1093/plankt/16.6.721

\section{DATA AVAILABILITY STATEMENT}

The raw data supporting the conclusions of this article will be made available by the authors, without undue reservation.

\section{AUTHOR CONTRIBUTIONS}

TC and CZ: conception and design of the study, provision of study materials, and analysis and interpretation of the data. TC: acquisition of data, drafting the manuscript, and final approval of the manuscript. TC, CZ, LR, and JJ: critical review of the manuscript. All authors contributed to the article and approved the submitted version.

\section{FUNDING}

This work was partially supported by a grant for the Ornamental Fish Innovation Team of Tianjin Mariculture System (ITTMRS2021004).

\section{ACKNOWLEDGMENTS}

The content of this manuscript formed a part of the Ph.D. thesis by TC (Camus, 2012). We would like to thank David McKinnon of Australian Institute of Marine Science, Townsville, for his instruction on how to use FlowCAM ${ }^{\mathrm{TM}}$ to determine algal density and his kindness in allowing us to use a Flow camera from his lab for this study.

Besiktepe, S., and Dam, H. G. (2002). Coupling of ingestion and defecation as a function of diet in the calanoid copepod Acartia tonsa. Mar. Ecol. Prog. S. 229, $151-164$.

Boxshall, G. A., and Halsey, S. H. (2004). An Introduction to Copepod Diversity. Ray Society Series 166. With S.H. Halsey. 2 Parts [Vols]. London: The Ray Society, 940.

Bunker, A. J., and Hirst, A. G. (2004). Fecundity of marine planktonic copepods: global rates and patterns in relation to chlorophyll a, temperature and body weight. Mar. Ecol. Prog. Ser. 279, 161-181. doi: 10.3354/meps279161

Camus, T. (2012). The Improvement of Copepods Intensive Culture Protocols as Live Feeds for Aquaculture Hatcheries. Ph. D, Thesis. Townsville, QLD: James Cook University, 148.

Camus, T., and Zeng, C. (2009). The effects of stocking density on egg production and hatching success, cannibalism rate, sex ratio and population growth of the tropical calanoid copepod Acartia sinjiensis. Aquaculture 287, 145-151. doi: 10.1016/j.aquaculture.2008.10.005

Camus, T., and Zeng, C. (2010). Roles of microalgae on total egg production over female lifespan and egg incubation time, naupliar and copepodite survival, sex ratio and female life expectancy of the copepod Bestiolina similis. Aquac. Res. 41, 1717-1726. doi: 10.1111/j.1365-2109.2010.02565.x

Camus, T., McKinnon, A. D., and Zeng, C. (2009). Egg production, egg hatching success and population increase of the tropical paracalanid copepod, bestiolina similis (calanoida: paracalanidae) fed different microalgal diets. Aquaculture 297, 169-175. doi: 10.1016/j.aquaculture.2009.09.018

Conceição, L. E., Yúfera, M., Makridis, P., Morais, S., and Dinis, M. T. (2010). Live feeds for early stages of fish rearing. Aquac. Res. 41, 613-640. doi: 10.1111/j. 1365-2109.2009.02242.x 
Corner, E. D. S., Head, R. N., and Kilvington, C. C. (1972). On the nutrition and metabolism of zooplankton. VIII. the grazing of biddulphia cells by Calanus helgolandicus. J. Mar. Biol. Assoc. U.K. 52, 847-861. doi: 10.1017/ S0025315400040595

Dadzie, S., Abou-Seedo, F., and Al-Qattan, E. (2000). The food and feeding habits of the silver pomfret Pampus argenteus (euphrasen), in kuwait water. J. Appl. Ichthyol. 16, 61-67.

Dagg, M. J., and Walser, W. E. Jr. (1986). The effect of food concentration on faecal pellet size in marine copepods. Limnol. Oceanogr. 31, 1066-1071. doi: 10.4319/lo.1986.31.5.1066

Dam, H. G., Peterson, W. T., and Bellantoni, D. C. (1994). Seasonal feeding and fecundity of the calanoid copepod Acartia tonsa in long island sound: is omnivory important to egg production? Hydrobiologia 292/293, 191-199. doi: 10.1007/978-94-017-1347-4_26

Dayras, P., Bialais, C., Lee, J. S., and Souissi, S. (2020). Effects of microalgal diet on the population growth and fecundity of the cyclopoid copepod Paracyclopina nana. J. World. Aquacult. Soc. 51, 1386-1401. doi: 10.1111/jwas.12685

Drillet, G., Jorgensen, N. O. G., Soresnsen, T. F., Ramlov, H., and Hansen, B. W. (2006). Biochemical and technical observations supporting the use of copepods as live feed organisms in marine larviculture. Aquac. Res. 37, 756-772.

Fenchel, T. (1974). Intrinsic rate of natural increase: the relationship with body size. Oecologia 14, 317-326. doi: 10.1007/BF00384576

Frost, B. W. (1972). Effects of size and concentration of food particles on the feeding behavior of the marine planktonic copepod Calanus pacificus. Limn. Oceanogr. 17, 805-815. doi: 10.4319/lo.1972.17.6.0805

Guillard, R. R. L., and Ryther, J. H. (1962). Studies on marine planktonic diatoms: I. cyclotella nana (hustedt), and detonula confervacea (cleve). Can. J. Microbiol. 8, 229-239. doi: 10.1139/m62-029

Guisande, C., Riveiro, I., and Maneiro, I. (2000). Comparison among the amino acid composition of females, eggs and food to determine the relative importance of food quantity and food quality to copepod reproduction. Mar. Ecol. Prog. Ser. 202, 135-142. doi: 10.3354/meps202135

Gusmão, L. F. M., and McKinnon, A. D. (2009a). Sex ratios, intersexuality and sex change in copepods. J. Plankton Res. 31, 1101-1117. doi: 10.1093/plankt/fbp059

Gusmão, L. F. M., and McKinnon, A. D. (2009b). The effect of food type and quantity on egg production and nucleic acid content of Acartia sinjiensis. Aquaculture 296, 71-80. doi: 10.1016/j.aquaculture.2009.08.015

Hirst, A. G., and Lampitt, R. S. (1998). Towards a global model of in situ weightspecific growth in marine planktonic copepods. Mar. Biol. 132, 247-257. doi: $10.1007 / \mathrm{s} 002270050390$

Holling, C. S. (1959). The components of predation as revealed by a study of small mammal predation of the European pine sawfly. Can. Entomol. 91, 293-320. doi: 10.4039/ent91293-5

Ismar, S. M. H., Hansen, T., and Sommer, H. (2008). Effect of food concentration and type of diet on Acartia survival and naupliar development. Mar. Biol. 154, 335-343. doi: 10.1007/s00227-008-0928-9

Jepsen, M., van Someren Grève, H., Jørgensen, K. N., Kjær, Kristine, G. W. B., and Hansen, W. (2021). Evaluation of high-density tank cultivation of the live-feed cyclopoid copepod Apocyclops royi (Lindberg 1940). Aquaculture 533:736125. doi: 10.1016/j.aquaculture.2020.736125

Jeschke, M., Kopp, M., and Tollrian, R. (2004). Consumer-food systems: why type I functional responses are exclusive to filter feeders. Biol. Rev. 79, 337-349. doi: $10.1017 /$ S1464793103006286

Jungbluth, M. J., Selph, K., Lenz, P. H., and Goetze, E. (2017). Species-specific grazing and significant trophic impacts by two species of copepod nauplii, Parvocalanus crassirostris and Bestiolina similis. Mar. Ecol. Prog. S. 572, 57-76. doi: 10.3354/meps 12139

Kiørboe, T., Møhlenberg, F., and Hamburger, K. (1985). Bioenergetics of the planktonic copepod Acartia tonsa: relation between feeding, egg production and respiration, and composition of specific dynamic action. Mar. Ecol. Progr. S. $26,85-97$.

Klein Breteler, W. C. M., and Gonzalez, S. R. (1982). Influence of cultivation and food concentration on body length of calanoid copepods. Mar. Biol. 71, 157-161. doi: 10.1007/BF00394624

Klein Breteler, W. C. M., and Gonzalez, S. R. (1988). Influence of temperature and food concentration on body size, weight and lipid content of two calanoid copepod species. Hydrobiology 16, 201-210. doi: 10.1007/BF00026306
Klein Breteler, W. C. N., Gonzales, S. R., and Schogt, N. (1995). Development of Pseudocalanus elongatus (copepoda, calanoida) cultured at different temperature and food conditions. Mar. Ecol. Prog. Ser. 119, 99-110. doi: 10. 3354/meps119099

Kleppel, G. S. (1992). Environmental regulation of feeding and egg production by Acartia tonsa off southern California. Mar. Biol. 112, 57-65. doi: 10.1007/ BF00349728

Koski, M., and Klein Breteler, W. (2003). Influence of diet on copepod survival in the laboratory. Mar. Ecol. Prog. Ser. 264, 73-82. doi: 10.3354/meps264073

Koski, M., and Kuosa, H. (1999). The effect of temperature, food concentration and female size on the egg production of the planktonic copepod Acartia bifilosa. J. Plankton Res. 21, 1779-1789. doi: 10.1093/plankt/21.9.1779

Liang, D., Uye, S., and Onbé, T. (1994). Production and loss of eggs in the calanoid copepod centropages abdominalis sato in fukuyama harbor, the Inland sea of Japan. Bull. Plankton Soc. Japan 41, 131-142.

Marcus, N. H., and Murray, M. (2001). Copepod diapause eggs: a potential source of nauplii for aquaculture. Aquaculture 201, 107-115. doi: 10.1016/S00448486(01)00514-2

Marcus, N. H., Richmond, C., Sedlack, C., Miller, G. A., and Oppert, C. (2004). Impact of hypoxia on the survival, egg production and population dynamics of Acartia tonsa dana. J. Exp. Mar. Biol. Ecol. 301, 111-128. doi: 10.1016/j.jembe. 2003.09.016

Mayzaud, P., and Poulet, S. A. (1978). The importance of the time factor in the response of zooplankton to varying concentrations of naturally occurring particulate matter. Limol. Oceano. 23, 1144-1154. doi: 10.4319/1o.1978.23.6. 1144

McKinnon, A. D., and Duggan, S. (2001). Summer egg production rates of paracalanid copepods in subtropical waters adjacent to Australia's North West Cape. Hydrobiologia 45, 121-132. doi: 10.1007/0-306-47537-5_10

McKinnon, A. D., Duggan, S., Nichol, P. D., Rimmer, M. A., Semmens, G., and Robin, B. (2003). The potential of tropical paracalanoid copepods as live feeds in aquaculture. Aquaculture 223, 89-106. doi: 10.1016/s0044-8486(03)00161-3

Milione, M., and Zeng, C. (2007). The effects of algal diets on population growth and egg hatching success of the tropical calanoid copepod, Acartia sinjiensis. Aquaculture 273, 656-664. doi: 10.1016/j.aquaculture.2007.07.014

Mitra, A., and Flynn, K. J. (2007). Importance of interactions between food quality, quantity, and gut transit time on consumer feeding, growth, and trophic dynamics. Am. Nat. 169, 632-646. doi: 10.1086/513187

Nogueira, N., Sumares, B., Nascimento, A. F., Png-Gonzalez, N., and Afonso, A. (2019). Effects of mixed diets on the reproductive success and population growth of cultured Acartia grani (Calanoida). J. Appl. Aquaculture. 33, 1-14. doi: 10.1080/10454438.2019.1602096

O’Bryen, P. J., and Lee, C. S. (2005). "Culture of copepods and applications to marine finfish larval rearing workshop discussion summary," in Copepods in Aquaculture, Blackwell Publishing, Melbourne, eds C. S. Lee, P. J. O'Bryen, and N. H. Marcus 245-255. doi: 10.1002/9780470277522.ch18

Pan, Y. J., Souissi, S., Souissi, A., Wu, C. H., Cheng, S. H., and Hwang, J. S. (2014). Dietary effects on egg production, egg-hatching rate and female life span of the tropical calanoid copepod Acartia bilobata. Aquac. Res. 45, 1659-1671. doi: 10.1111 /are.12113

Payne, M. F., and Rippingale, R. J. (2001). Intensive cultivation of the calanoid copepod gladioferens imparipes. Aquaculture 201, 329-342. doi: 10.1016/ s0044-8486(01)00608-1

Peterson, W. T., and Painting, S. J. (1990). Developmental rates of the copepods Calanus australis and Calanoides carinatus in the laboratory, with discussion of methods used for calculation of development time. J. Plank. Res. 12, 283-293. doi: $10.1093 /$ plankt/12.2.283

Rasdi, N. W., and Qin, J. G. (2016). Improvement of copepod nutritional quality as live food for aquaculture: a review. Aquac. Res. 47, 1-20. doi: 10.1111/are. 12471

Rasdi, N. W., and Qin, J. G. (2018). Impact of food type on growth, survival and reproduction of the cyclopoid copepod cyclopina kasignete as a potential live food in aquaculture. Aquac. Inter. 26, 1281-1295. doi: 10.1007/s10499-0180283-x

Sampey, A., McKinnon, A. D., Meekan, M. G., and McCormick, M. I. (2007). Glimpse into guts: overview of the feeding of larvae of tropical shore fishes. Mar. Ecol. Prog. Ser. 339, 243-257. doi: 10.3354/meps339243 
Shubert, P., Vogt, L., Eder, K., Hauffe, T., and Wilke, T. (2016). Effects of feed species and HUFA composition on survival and growth of the longsnout seahorse (hippocampus reidi). Front. Mar. Sci. 3:53. doi: 10.3389/fmars.2016. 00053

Shansudin, L., Yusof, M., Azis, A., and Shukri, Y. (1997). The potential of certain indigenous copepod species as live food for commercial fish larval rearing. Aquaculture 151, 351-357. doi: 10.1016/S0044-8486(96)01 490-1

Støttrup, J. G. (2000). The elusive copepods: their production and suitability in marine aquaculture. Aquac. Res. 3, 702-711. doi: 10.1046/j.1365-2109.2000. 318488.x

Støttrup, J. G., and Jensen, J. (1990). Influence of algal diet on feeding and eggproduction of the calanoid copepod Acartia tonsa Dana. J. Exp. Mar. Biol. Ecol. 141, 87-105. doi: 10.1016/0022-0981(90)90216-Y

Strathmann, R. R. (1967). Estimating the organic carbon content of phytoplankton from cell volume or plasma volume. Limnol. Oceanogr. 12, 411-418. doi: 10. 4319/lo.1967.12.3.0411

Tirelli, V., and Mayzaud, P. (2005). Relationship between functional response and gut transit time in the calanoid copepod Acartia clausi: role of food quantity and quality. J. Plankton Res. 27, 557-568. doi: 10.1093/plankt/fb i031

Uye, S. I. (1981). Fecundity studies of neritic calanoid copepods Acartia clausi giesbrecht and a. steueri smirnov: a simple empirical model of daily egg production. J. Exp. Mar. Bio. Ecol. 50, 255-271. doi: 10.1016/0022-0981(81) 90053-8

VanderLugt, K., and Lenz, P. H. (2008). Management of nauplius production in the paracalanoid, bestiolina similes (crustacean: copepoda): effect of stocking densities and culture dilution. Aquaculture 276, 69-77. doi: 10.1016/ j.aquaculture.2008.01.041

VanderLugt, K., Cooney, M. J., Lechner, A., and Lenz, P. H. (2009). Cultivation of the paracalanid copepod, bestiolina similis (calanoida: crustacea). J. World. Aquacult. Soc. 40, 616-628. doi: 10.1111/j.1749-7345.2009.00282.x
Xu, Y., and Wang, W. X. (2001). Individual responses of trace element assimilation and physiological turnover by the marine copepod Calanus sinicus to change in food quantity. Mar. Ecol. Prog. Ser. 218, 227-238. doi: 10.3354/meps218227

Yúfera, M., Ortiz-Delgado, J. B., Hoffman, T., Siguero, I., Urup, B., and Sarasquete, C. (2014). Organogenesis of digestive system, visual system and other structures in Atlantic bluefin tuna (Thunnus thynnus) larvae reared with copepods in mesocosm system. Aquaculture 426-427, 126-137. doi: 10.1016/j.aquaculture. 2014.01.031

Zeng, C., Shao, L., Ricketts, A., and Moorhead, J. (2018). The importance of copepods as live feed for larval rearing of the green mandarin fish Synchiropus splendidus. Aquaculture 491, 65-71. doi: 10.1016/j.aquaculture.2018.03.011

Zhang, J., Ianora, A., Wu, C., Pellegrini, D., Esposito, F., and Buttino, I. (2015). How to increase productivity of the copepod Acartia tonsa (dana): effects of population density and food concentration. Aquac. Res. 46, 2982-2990. doi: 10.1111 /are.12456

Conflict of Interest: The authors declare that the research was conducted in the absence of any commercial or financial relationships that could be construed as a potential conflict of interest.

Publisher's Note: All claims expressed in this article are solely those of the authors and do not necessarily represent those of their affiliated organizations, or those of the publisher, the editors and the reviewers. Any product that may be evaluated in this article, or claim that may be made by its manufacturer, is not guaranteed or endorsed by the publisher.

Copyright (C) 2021 Camus, Rolla, Jiang and Zeng. This is an open-access article distributed under the terms of the Creative Commons Attribution License (CC BY). The use, distribution or reproduction in other forums is permitted, provided the original author(s) and the copyright owner(s) are credited and that the original publication in this journal is cited, in accordance with accepted academic practice. No use, distribution or reproduction is permitted which does not comply with these terms. 